\title{
QUEM GIROU AS CHAVES DA INTERNACIONALIZAÇÃO DOS CURRÍCULOS NA EDUCAÇÃO BÁSICA?
}

\author{
JUARES DA SILVA THIESEN ${ }^{1 *}$ \\ ORCID: https://orcid.org/0000-0001-9299-4441
}

RESUMO: No texto, identifico e analiso um conjunto de iniciativas de largo impacto envolvendo formação escolar, as quais, em distintos aspectos, configuram marcas do surgimento e da consequente expansão da internacionalização dos currículos nos territórios da Educação Básica em escala mundial. Exploro, ademais, as racionalidades epistêmicas, pedagógicas e políticas que mobilizam tais projetos, bem como as influências que exercem, particularmente, sobre a política curricular oficial brasileira. Tratase de um estudo exploratório de natureza empírico-teórica que, recorrendo à literatura impressa e às bases de dados disponíveis nas redes digitais, utiliza predominantemente trabalhos já realizados em contextos internacionais como fontes primárias. Os resultados indicam que, embora os projetos sejam predominantemente de iniciativa não estatal, suas influências alcançam com força vários sistemas nacionais de educação, inclusive o do Brasil.

Palavras chave:Currículo. Internacionalização. Escolas Internacionais. Bacharelado internacional.

WHO OPENED THE DOORS TO THE INTERNATIONALIZATION OF BASIC EDUCATION'S CURRICULUM?

ABSTRACT: In this paper I identify and analyze a group of initiatives that have strong impacts on school education, and that in different ways mark the rise and expansion of internationalization of basic education's curriculum on a global scale. I also explore epistemic, pedagogical and political realities that mobilize these projects, as well as the influences that they have, particularly on official Brazilian curriculum policy. This is an exploratory study of an empiric-theoretical nature that, using literature books and databases available on digital networks, focuses predominantly on studies conducted in international contexts as primary sources. The results indicate that although most of the projects are non-state initiatives, they have a strong influence on various national education systems, including Brazil's.

Keywords: Curriculum. Internationalization. International Schools. International Bachelor's Degree.

\footnotetext{
${ }^{1}$ Universidade Federal de Santa Catarina, Florianópolis, SC, Brasil.
}

"Doutor em Educação. Professor pesquisador do Programa de Pós-Graduação em Educação do Centro de Ciências da Educação da Universidade Federal de Santa Catarina - UFSC. Líder do Grupo de Pesquisa em currículo - ITINERA. Email:<juares.thiesen@ufsc.br > . 


\section{INTRODUC̣̃̃O}

Que movimento é esse que tão rapidamente inunda, em dimensões transoceânicas, os territórios educacionais na Educação Superior e vai sedutoramente envolvendo também os currículos da Educação Básica? Onde estão situados os epicentros desse fenômeno social cujos efeitos se propagam com gigantesca força em escala global? Que impactos pedagógicos, políticos e culturais esse movimento produz nos sistemas de ensino e nos ambientes educacionais de tantos países e, inclusive, do Brasil? Será esse o projeto que poderá colocar a utopia de uma educação de qualidade num horizonte mais próximo e, portanto, factível? Ou se trata, fundamentalmente, de um movimento construído no contexto dos globalismos contemporâneos por redes políticas transnacionais, organismos multilaterais e grandes empresas, como estratégia (ainda pouco explicitada) de apropriação e controle da educação-negócio-mercadoria?

São questões que atravessam o percurso da investigação que desenvolvo no estágio Pós-doutoral na Universidade do Minho/Portugal, que tem por objetivo analisar os impactos da internacionalização da Educação Superior sobre os currículos da Educação Básica, ${ }^{1}$ especialmente nos contextos de Brasil e Portugal. No presente texto, como recorte, destaco pontos que sinalizam a origem dos movimentos pela internacionalização da educação e que envolvem os currículos da Educação Básica - nível de ensino que inclui as etapas da Educação Fundamental (elementar e/ou primária - dependendo do país) e o Ensino Médio (ou Educação Secundária).

O trabalho soma-se a outros já formulados no âmbito dessa mesma pesquisa, quando explorei respectivamente: i) aspectos conceituais e contextuais dos movimentos pela internacionalização envolvendo Educação Superior e Básica;ii) principais estratégias adotadas por Estados-nação e iniciativa privada para ajustarem seus sistemas de educação e escolas às demandas e requerimentos da internacionalização, iii) influências dos discursos educacional e acadêmico global $(\mathrm{BECCH}$, 2012) nos contextos de formulação dos textos das políticas curriculares, especialmente no Brasil e, iv) o cosmopolitismo como fundamento utopia nos projetos de internacionalização da educação.

Os resultados da pesquisa que apresento nas seções desse artigo, incluem sucessivamente: a identificação de contextos nos quais os movimentos pela internacionalização dos currículos da Educação Básica se originam e projetam expressão em escala global; 
as racionalidades epistêmicas e políticas que sustentam e mobilizam tais movimentos e, finalmente, aspectos que sugerem, neste mesmo âmbito, aproximações e alinhamentos da Educação Básica brasileira às demandas, expectativas e requerimentos da internacionalização. Trata-se de um estudo exploratório de natureza empírico-teórica que, recorrendo à literatura e às bases de dados disponíveis nas redes digitais, utiliza predominantemente trabalhos já realizados em contextos internacionais como fontes primárias. $^{2}$

\section{SOBRE A ORIGEM E MOTIVAÇ̃̃ES DO MOVIMENTO PELA ICEB ${ }^{3}$}

Suponho ser relativamente corrente na comunidade científica que discute política educacional, a compreensão que movimentos de natureza educacional (como é o caso da internacionalização) ou de qualquer outra que envolva grupos sociais e processos complexos, não podem ser cronologizados na lógica dos tempos convencionais. Em geral, suas raízes, motivações e influências podem ser, de algum modo e intensidade, encontradas sempre além e mais profundamente do que imaginamos. A afirmação serve apenas para marcar que, tendo consciência dessa limitação, considero na pesquisa, como origens e motivações dos movimentos pela ICEB tão somente iniciativas de alguma forma indicadas na literatura com este propósito e movidas em contextos de formulação/proposição de políticas educacionais e curriculares.

Feita a demarcação, passo a situar o conjunto de iniciativas oficiais e não estatais que indicam o surgimento e emergência dos movimentos pela ICEB. Trata-se de um fenômeno recente (Sec. XIX/ $\mathrm{XX}$ ) que envolve o mundo educacional público e privado e move-se em meio a outros processos sociais igualmente complexos, dentre os quais a mundialização/globalização do capital, a transnacionalização das redes políticas internacionais, os rearranjos das estruturas estatais dos estados nacionais frente às ameaças terroristas e os fluxos dos movimentos migratórios, as novas demandas geradas pelas tecnologias num mundo que percebe hiperconectado e a força das questões culturais que tensionam as relações sociais, especialmente às ligadas à raça, gênero e diversidade.

São contextos que vêm impondo a necessidade de outros arranjos de governabilidade, tanto nas estruturas estatais de poder, quanto em outras instâncias da sociedade civil e do próprio mercado. Cenários que no âmbito da política educacional, estimulam estados nacionais e 
organismos transnacionais a impulsionar, com força, os movimentos pela internacionalização da Educação Superior (Higher Education) e que, mantendo racionalidades similares em termos de estratégias e finalidades, também mobilizam, por extensão, ações na direção da ICEB.

Constata-se que as iniciativas com maior potencial de propagação overseas e que reúnem os argumentos mais convincentes junto aos espaços nacionais de poder político e nas redes dos organismos transnacionais, são aquelas formuladas e implantadas nos e por países economicamente centrais que, em geral, exibem bons indicadores educacionais e que já estabeleceram parcerias com a iniciativa privada. São nesses espaços que se fortalece a chamada governança transnacional com acentuado interesse na educação e que, por intermédio de suas organizações, vai hegemonizando discursos globais sobre 'o que deve ser' e o 'como se deve fazer' na educação para atender demandas e expectativas da internacionalização.

De modo geral, se pode afirmar que as ações mais significativas orientadas para o currículo da Educação Básica, neste âmbito, estão integradas por três importantes projetos os quais, sob a força dos discursos em torno da global citizenship education in the context of dimension global education (YEMINI, 2017) alcançam significativas influências. São eles, respectivamente: a criação e expansão das chamadas Escolas Internacionais; a criação e expansão do International Baccalaureate com seu Diploma Programme (IB-DP) e outras ações; e a propagação de agências ou organizações que oferecem suporte, assessoramento e gerenciamento às redes de escolas internacionais.

Sem a pretensão de explorar exaustivamente cada um, destacarei tão somente aspectos sobre o que propõem, de modo a indicar seus potenciais em termos de influência política nos contextos da internacionalização da educação.

\section{ESCOLAS INTERNACIONAIS - EI}

O currículo de uma Escola Internacional deve ser a destilação do melhor conteúdo e da mais efetiva prática instrucional de cada um dos sistemas nacionais de educação. (TERWILLIGER, 1972)

O conceito de escola internacional vem sendo discutido especialmente por pesquisadores que analisam a problemática educacional nos contextos de transnacionalização einternacionalização, e de modo particular por aqueles que focam atenção nos movimentos que envolvem os currículos da Educação Básica. Destacam-se 
neste âmbito, nomes como: Bunnell (2011, 2013, 2014); Brummitt (2007), Brummitt e Kelling (2013), Hayden (2011); Hayden, Levy e Thompson (2015), Hill (2015), Yemini (2015, 2017), além de vários outros. Dentre os aspectos de análise da problemática, aparece com força: a questão da legitimidade ${ }^{4}$ desta tipologia escolar na relação com a tradição dos sistemas de ensino de países que desenvolvem essa experiência curricular na formação elementar ou secundária; elementos organizacionais e curriculares que as identificam e caracterizam como Escolas Internacionais; potencial de inovação curricular que manifestam e razões de seu exponencial crescimento no mundo todo.

No denso trabalho que faz sobre internacionalização da educação e cidadania global e tomando Israel como território de análise, Yemini (2017) é enfática ao afirmar que nas escolas a dimensão internacional da educação está intimamente relacionada com habilidades e avanços demandados no século XXI e que a preparação da juventude para a cidadania ativa, móvel, dinâmica e global está sendo reivindicada como um dos principais desafios dos sistemas educacionais em muitos países. Nesse sentido, tanto as Escolas Internacionais (EI) quanto os Programas do International Baccalaureate (IB) vêm desempenhando papéis importantes.

As escolas que se assumem com essa tipologia (EI) desenvolvem experiências curriculares que pretendem ser consideradas referências de internacionalização dos currículos na Educação Básica. Lauder (2015) arrisca-se a usar a expressão international schools sistems (ISS) para marcar a força dessa rede na relação com os sistemas tradicionais de ensino. São escolas que geralmente incorporam o desenvolvimento da cidadania global em suas declarações de missão, o que implica que preparam seus alunos para se tornarem membros de uma sociedade global (YEMINI, 2017). Com essa perspectiva e sem as amarras do ensino focado em conteúdos dos contextos locais, pautam seus currículos na aquisição das chamadas competências interculturais e globais. Pelo poder de sedução que exercem junto às comunidades e famílias, se espalham rapidamente pelo planeta num exponencial crescimento tanto no número de oferta de escolas quanto de estudantes.

Hayden e Tompson (2013) apontam que o crescimento que vinha sendo discreto até a primeira metade do Século XX e que sofreu um boom a partir da segunda, deve-se especialmente pela mobilidade de profissionais que, por força da globalização, transitam mais frequentemente pelo planeta; pelo fato de o inglês tornar-se o principal idioma internacional e ainda pela busca deste tipo de 
escola pelas famílias de maior poder aquisitivo tendo em vista as possibilidades de acesso de seus filhos às melhores universidades - um horizonte que inclui colocá-los em vantagem num mundo competitivo. Avaliam que o crescimento das EI, associado à força da globalização, tem influenciado sobremaneira os sistemas nacionais de educação básica, especialmente os planejadores e formuladores de políticas oficiais em relação à importância da internacionalização.

Sobre características e expansão das EI, Bunnell, Fertig e James (2016) levantam uma questão que pode ser uma chave conceitual importante. Eles perguntam: What is international about International Schools? Amparando-se, inclusive, em trabalhos de outros pesquisadores, classificam as escolas internacionais em três categorias, as quais, segundo eles, correspondem, em significativa medida, às suas fases de expansão. ${ }^{5}$ As de tipo A, consideradas tradicionais, são escolas criadas ainda no Século XIX, nos anos $1860^{6}$ para oferecer educação aos filhos de pais migrantes com diversos ofícios e, portanto, para atender à formação escolar em diferentes experiências e perspectivas culturais. As do tipo B foram sendo criadas posteriormente sob a ideologia do fortalecimento da paz e da mentalidade internacional (international-mindedness) ${ }^{7}$, sendo estas as primeiras a oferecer o IB (International Baccalaureate).

Finalmente, as do tipo $\mathrm{C}$ são as que se reconfiguraram a partir dos modelos anteriores incorporando características e abordagens distintas tais como: são predominantemente privadas e com interesses lucrativos; atendem crianças de famílias locais com aspiração à ascensão de classe social e/ou filhos de pais ricos e, na sua maioria, foram absorvidas por grandes empresas ou fundações com ou sem fins lucrativos, a exemplo do que desenvolve a Global Education Management Systems - GEMS, que criou uma rede e que atualmente possui escolas internacionais em 13 países conforme exibe seu próprio site. As IE de tipo C têm sido cada vez mais suportadas por agências ou organizações não estatais, com ou sem fins lucrativos, que fazem o gerenciamento educacional das redes de escolas internacionais como é o caso da International Schools Services (ISS), além de tantas outras. ${ }^{8}$

Os referidos autores destacam que tanto o rápido crescimento quanto as mudanças sobre o que consistem as escolas internacionais tornam-se mais substantivas e significativas e, portanto, começam a afetar os sistemas nacionais de educação, especialmente no que se refere ao cumprimento (ou não) das normas oficiais dos países. Entendem que por essas e outras razões, as fronteiras que definem se uma escola é ou não internacional são ainda tênues. 
Amparados em estudos de Brummitt (2009), Pearce (2013), Hayden and Thompson (2008, 2013) e outros, levantam uma série questões que mostram como este conceito ainda é frágil, especialmente quando se trata da definição sobre o que caracteriza uma legítima escola internacional. Nesse aspecto, Bunnell, Fertig e James (2016) problematizam o fato de escolas situadas fora de países de língua inglesa requererem status de internacional somente por desenvolverem seus currículos no idioma inglês; indagam sobre como estas escolas lidam com as questões da diversidade cultural; sobre como os sistemas de ensino vêm se posicionado no que se refere à acreditação de componentes curriculares, publicação de resultados de aprendizagem e atendimento às normas.

Para os pesquisadores a ideia de legitimidade institucional que deveria caracterizar uma EI tem a ver com a congruência entre aquilo que as instituições com essa tipologia propõem e desenvolvem na formação dos estudantes e os comportamentos e valores aceitáveis pelos sistemas sociais mais amplos e, sobretudo, com o atendimento aos princípios e definições dos sistemas nacionais de educação. Certamente, escolas que têm essencialmente a lógica do lucro e da competição como perspectiva tendem a ficar de fora deste ambiente de aprovação social mais amplo, principalmente porque não conseguem adequar-se a estes elementos da tradição que marcam a existência histórica da escola como instituição pública. De todo modo, são fundamentalmente as Escolas Internacionais que materializam o conceito de internacionalização na formação de estudantes no nível da Educação Básica e que vêm atraindo parte significativa das famílias das camadas sociais mais favorecidas em vários cantos do mundo.

\section{O INTERNATIONAL BACCALAUREATE (IB)}

Diretamente associado ao projeto das Escolas Internacionais, está o que desenvolve a Fundação IB, organização sem fins lucrativos, criada em Genebra em 1968 e que inclui, dentre seus objetivos, desenvolver pessoas de mentalidade internacional e entendimento multicultural que, reconhecendo sua humanidade comum e a guarda compartilhada do planeta, ajudem a criar um mundo melhor e mais pacífico. Com essa missão de criar um mundo melhor através da educação, atua com escolas, governos e organizações internacionais visando apoiar e desenvolver programas curriculares de educação internacional. (IB, 2018). Segundo avalia Yemini (2017), nas últimas décadas o IB tornou-se, no mundo todo, o mais importante instrumento de credenciamento das EI e o mais 
bem conceituado mecanismo de estreitamento do acesso de estudantes da Educação Secundária à Superior.

Conforme mostram os números da própria fundação, em 2018, o IB desenvolve seus programas para atender aproximadamente 1.400.000 estudantes em 4.775 escolas, em 153 países. Dados de 2016 indicam que $56 \%$ do total de escolas pertenciam às redes oficiais de ensino e $44 \%$ à iniciativa privada. Dentre seus principais programas estão o Diploma Program (IB-DP), instituído desde 1968 com a criação da organização; o Middle Years Programme (IB-MYP) lançado em 1994, o Primary Years Programme (IB-PYP) implantado em 1997, o Learner Profile (IB-LP) instituído em 2006 e o Career-related Programme (IB-CP) introduzido a partir de 2012 (IB, 2018). ${ }^{9}$

Dentre os objetivos dos programas desenvolvidos no âmbito do IB e destacados no seu Program IB-Learner Profile, está o de "develop internationally minded people who, recognizing their common bumanity and shared guardianship of the planet, help to create a better and more peaceful world” (IB, 2018). Seus formuladores afirmam que o IB Learner Profile expressa os dez atributos ${ }^{10}$ avaliados pelas Escolas do Mundo do IB e acrescentam que apostam nestes atributos com a crença que eles podem ajudar indivíduos e grupos a se tornarem membros responsáveis de comunidades locais, nacionais e globais.

Para Hill (2015) o International Baccalaureate (IB) foi, no século $\mathrm{XX}$, o projeto catalisador da filosofia do international-mindeness ${ }^{11}$ expressão utilizada pela primeira vez em 1951 durante uma conferência realizada em Paris e convocada pela UNESCO para discutir educação internacional e que atualmente é aceita para caracterizar os princípios que sustentam Escolas Internacionais (privadas ou estatais) que oferecem educação internacional.

Hill (2015) destaca que o IB, por intermédio da caracterização do programa IB-Learner Profile, reafirma seu ideário de formação escolar em três pilares: i) por princípios humanistas que marcaram a tradição das antigas civilizações, particularmente a oriental e a grega, ii) por insights pedagógicos de pensadores da modernidade como os de Montaigne, Comenius, Pestalozzi, Rousseau e outros e, iii) por conhecimentos, culturas e tecnologias do contemporâneo. Sobre essa base combinam hoje: compreensão intercultural, aprendizagem de línguas, direitos humanos, educação pela paz, cooperação internacional, consciência de questões globais e desenvolvimento sustentável.

Para Yemini (2017), o IB, assim como outras iniciativas de propósito semelhante, está situado em meio a um dilema que 
enfrentam os sistemas nacionais de educação, qual seja, conciliar as demandas educacionais de um currículo nacional e local, com os requerimentos transnacionais de uma educação que pretende ser internacionalizada. Não obstante, a autora destaca que os sistemas educacionais nacionais têm respondido a isso, promovendo cada vez mais agendas de internacionalização orientadas para superar a limitação. Com essa perspectiva, amplia-se o quadro de conceitos envolvendo educação para a cidadania global, o apoio à professores através de iniciativas orientadas para um currículo internacional, além de outras atividades neste mesmo horizonte. São movimentos que induzem debates cujas pautas colocam na mesa outros dilemas sobre o que a educação internacional realmente significa.

O IB é, notadamente, um projeto que pretende representar o que há de mais internacional na formação de estudantes neste nível de ensino. Sobre este aspecto, Roberts (2015) destaca que os projetos que mobilizam a educação internacional, especialmente o IB, realizam permanente monitoramento dos sistemas de educação para identificar, dentre outros elementos, quais mudanças e atualizações curriculares e quais conteúdos e abordagens acompanham os processos de ajustes ou reformas em perspectivas globais. É também sobre esta dinâmica que organizações como o IB propõem revisões curriculares e tematizam suas conferências programáticas.

Outro ponto interessante refere-se às convergências entre o que propõe o IB em seus programas e as formulações de organismos transnacionais como a OCDE e a UNESCO. Sobre este aspecto, Roberts (2015) afirma que IB mantém-se permanentemente atento aos relatórios dessas organizações ao tempo em que seus programas e conferências reciprocamente alimentam discussões e proposição de revisões por parte destes mesmos organismos. Além disso, afirma que o IB é frequentemente abordado por organizações não governamentais visando permissão de uso de seus materiais e recursos. Destaca ainda que os quatro programas do IB têm sido de algum modo, referência para promover o que chama de um continuous da educação internacional e que o acentuado crescimento das escolas IB somado à capacidade de atração dos programas, refletem o grau de influência que o IB vem produzindo sobre os currículos do ensino básico nos sistemas oficiais.

Yemini (2017) assim como Roberts, acentua a força do IB frente aos sistemas de educação e descreve o currículo de seus programas como sendo um processo relativamente simples. ${ }^{12}$ Destaca ainda que o IB-DP possui dois proeminentes motivos para tornar-se importante 
no contexto da educação internacional neste nível de ensino e que ambos convergem com a missão da organização: primeiro porque é reconhecido pelas instituições de educação superior e segundo porque pauta-se por uma visão idealista de formação escolar cultivando os fundamentos tradicionais das humanidades e das ciências exatas como suas pedras angulares. Ou seja, o IB-DP alinha-se às questões de grande importância que vem sendo atribuidas pelas redes de governança transnacionais no contexto do que tem sido chamado de educação global. A influência do IB-DP é tão substantiva que a Austrália chegou a apresentá-lo como alternativa para o programa nacional de educação e Israel discute a possibilidade de implantá-lo no seu sistema oficial de ensino. (DOHERTY, 2009 e YEMINI, 2015).

\section{AGÊNCIAS E REDES DE GERENCIAMENTO DAS ESCOLAS INTERNACIONAIS E SEUS CREDENCIAMENTOS}

Como já destaquei, as Escolas Internacionais do tipo C foram muito rapidamente absorvidas por grandes organizações de interesse privado (com ou sem fins lucrativos) e por universidades que já desenvolviam projetos de educação internacional nos moldes tradicionais (tipos A e B) e que também foram agregando outras ações e, portanto, mudando suas características tanto no assessoramento quanto na oferta escolar.

Tanto a criação e o exponencial crescimento das EI quanto das networks para seu gerenciamento, precisam ser vistos como parte de um projeto maior - o transnacionalismo globalizante que, dentre outras coisas, demanda a formação de trabalhadores globais, hegemoniza discursos da cidadania global, estimula o fortalecimento de corporações multinacionais e de organizações não governamentais e coloca em marcha os movimentos pela internacionalização da educação nos níveis superior e básico (LAUDER, 2015). Portanto, a expansão vertiginosa, pelos quatro cantos do planeta, dessas agências e redes de atendimento educacional e escolar, sustentadas que são pelo pilar da internacionalização, evidenciam a força desses movimentos no contemporâneo. A título de exemplificação mostro, no quadro a seguir, alguns desses fluxos, especialmente no que se refere as tendências, expectativas, requerimentos e demandas que são mobilizadas nesses contextos. 
QUADRO 1 Contextos nos quais se inscrevem os movimentos pela internacionalização do currículo da Educação Básica.

\begin{tabular}{|l|l|}
\hline \multicolumn{1}{|c|}{ Escalas/Âmbitos } & \multicolumn{1}{c|}{ Movimentos } \\
\hline $\begin{array}{l}\text { Tendências mundiais em } \\
\text { âmbito macrosocial }\end{array}$ & $\begin{array}{l}\text { Globalização; transnacionalização; cosmopolitismo liberal; } \\
\text { mercados internacionais; mobilidades de fluxo intenso. }\end{array}$ \\
\hline $\begin{array}{l}\text { Tendências e perspectivas } \\
\text { mundiais no âmbito } \\
\text { da educação }\end{array}$ & $\begin{array}{l}\text { Educação global; redes de governança transnacional } \\
\text { (organismos multilaterais); internacionalização. }\end{array}$ \\
\hline $\begin{array}{l}\text { Demandas e expectativas } \\
\text { educacionais em contextos } \\
\text { de internacionalização }\end{array}$ & $\begin{array}{l}\text { Cidadania global; international-mindedness; currículos } \\
\text { internacionalizados; standardização de resultados; isomorfismo } \\
\text { curricular; performatividade. }\end{array}$ \\
\hline $\begin{array}{l}\text { Demandas e expectativas } \\
\text { em contextos de } \\
\text { internacionalização } \\
\text { do currículo }\end{array}$ & $\begin{array}{l}\text { Competências globais e interculturais; competição } \\
\text { por credenciais de qualidade institucional; currículo } \\
\text { internacionalizado; elevação de rankings internacionais; oferta } \\
\text { de passaportes para ingresso de estudantes nas melhores } \\
\text { universidades ou empregabilidade. }\end{array}$ \\
\hline
\end{tabular}

Fonte: elaboração do autor com base nos autores citados no texto.

As agências ou redes de gerenciamento, em razão do conjunto de ações que realizam, podem ser classificadas em dois tipos: aquelas que possuem suas próprias escolas e, portanto, projetam e desenvolvem formação escolar em suas unidades, a exemplo do que fazem a Cambridge International School que desde 2015 integrouse à International Schools Partnership; a Stanford International School, a Viena Internacional School; a Eastern Mediterranean International School (EMIS), além de várias outras. E aquelas que, não possuindo escolas próprias, oferecem serviços de suporte e apoio por intermédio do gerenciamento de diferentes serviços educacionais, participando efetivamente da formulação curricular das escolas conveniadas, como é o caso da Nobel Education Network, do Council of International Schools (CIS), da Nordic Network Internacional Schools, da New England Association of Schools and Colleges (NEASC), da Network of International Christian Schools, da Nord Anglia Education, da National Association of British Schools in Spain (NABSS), da Association of German International Schools (AGIS), da The National Association of Independent Schools (NAIS), dentre outras. Hayden e Tompson (2015) lembram que apesar de as escolas possuírem autonomia para projetar e desenvolver seus próprios currículos, a maioria delas opta por oferecer currículos já desenvolvidos 
por agências externas. Em geral, as agências ou organizações criadas com esta finalidade desenvolvem um portfólio de trabalho que inclui, dentre outras ações, acreditação de escolas como EI, avaliação por meio de exames atendendo padrões internacionais, monitoramento de processos e resultados, aconselhamento no âmbito da gestão e das decisões curriculares, seleção de professores, realização de eventos, qualificação de staffs, desenvolvimento de planejamentos estratégicos e de programas acadêmicos, estabelecimento de interfaces entre escolas da mesma rede e das escolas com outros espaços internacionais, estabelecimento de Standards etc. Todas com a promessa de alcance de alta qualidade educacional e curricular. O Council of International Schools (CIS), por exemplo, conforme anunciado em seu website, assume o compromisso de uma educação internacional de alta qualidade e para tanto, desenvolve gerenciamento para 733 escolas e 80 colleges e universidades em 116 países (CIS, 2018).

No escopo de trabalho das redes de apoio e gerenciamento das escolas que pretendem ou consideram ser internacional, destacase o aspecto da acreditação internacional (AI), processo que tem sido altamente valorizado por escolas e redes quando apresentam sua distinção em relação às demais instituições educativas dos sistemas oficiais de ensino. O certificado de acreditação juntamente e o diploma $\mathrm{IB},{ }^{13}$ são os instrumentos que objetivamente definem a linha de fronteira entre ser ou não ser uma escola reconhecidamente internacional. Fertig (2007) analisa a vertiginosa expansão dos processos de acreditação de EI e ressalta que mesmo sendo opção das escolas, o certificado é visto como expressão de distinção e de alta qualidade.

Outro aspecto importante apontado por Fertig (2007) referese à influência dos processos de acreditação das EI sobre os sistemas nacionais de ensino. Afirma que os modelos de acreditação que, em geral, misturam autoavaliação ou avaliação interna com exames externos espelham o que adotam os setores públicos, ainda que estes tenham autonomia para escolher o caminho de acreditação no rol das organizações que oferecem este serviço. Esse alinhamento, do ponto de vista dos standards com os processos de avaliação em larga escala que desenvolvem os sistemas públicos de educação revela que ambos os setores se orientam pela mesma lógica quando o tema é aferição de resultados educacionais e escolares.

Autores que analisam o crescimento e as influências das Escolas Internacionais, bem como das diferentes estratégias criadas por organizações não estatais para fortalecer esse sistema 
paralelo de educação via fornecimento de credenciais (certificação ou acreditação), mostram-se consensuais quanto ao expressivo potencial de influência que esse sistema exerce sobre a formulação e desenvolvimento de políticas educacionais e curriculares nos sistemas oficiais dos Estados-nação. Entendem que isso ocorre porque esse 'sistema paralelo' parece responder mais eficientemente às demandas dos requerimentos internacionais postos notadamente pelas redes políticas transnacionais. São requerimentos que, dentre outros aspectos, apelam para o estabelecimento de padrões educacionais de níveis cada vez mais elevados nos rankings das performances em termos de resultados de aprendizagem dos estudantes. Demanda que, não por acaso, é ponto de referência e ideário das Escolas Internacionais e das redes de gerenciamento que lhes dão sustentação.

Paralelamente às iniciativas mais largamente conhecidas como as que deram origem e continuam induzindo a expansão dos projetos de internacionalização dos currículos na Educação Básica e que, por isso, pretendem representar o que há de mais original, avançado e inovador no campo da proposição, desenvolvimento e avaliação curricular na formação escolar de crianças e jovens em perspectiva de internacionalização, outras de menor impacto também aparecem na literatura, dentre as quais movimentos e programas como o World Class School (REYNOLDS et al, 2004), o School Improvement (HOPKINS, 2004) e o Charters Schools (ADRIÃO, 2014). São proposições que assumindo referenciais de um discurso educacional global (BEECK, 2012), colocam em convergência interesses de expressivos grupos e organizações que se movem em escala mundial, seja no âmbito da iniciativa privada ou do Estado. ${ }^{14}$.

\section{REFLEXOS DOS MOVIMENTOS PELA ICEB NOS CONTEXTOS DA POLÍTICA CURRICULAR BRASILEIRA}

Em outros textos dessa mesma pesquisa tenho mostrado que dados empíricos extraídos de conteúdos de programas educacionais e de textos da política curricular formulados para a Educação Básica brasileira, revelam fortes evidências de um progresso alinhamento pedagógico, ideológico e político do sistema educacional do país aos requerimentos, demandas e expectativas da internacionalização e que, portanto, o Brasil acompanha uma tendência educacional que tem sido seguida em escala global notadamente influenciada pelos discursos das redes de governança transnacional as quais, assumido 
a condição de grupo educacional dirigente, se autoriza a estabelecer critérios de avaliação em larga escala, definir padrões de qualidade de aprendizagem, propor mecanismos de regulação e monitoramento de processos escolares e inclusive prescrever currículos para os sistemas de ensino de países em todos os cantos do planeta.

Com base na presente investigação e apoiado na literatura que discute a problemática, tenho afirmado que as racionalidades epistêmicas e políticas de cunho (neo)liberal que sustentam os movimentos de internacionalização da Educação Superior são as mesmas que vêm orientando estados nacionais a alinharem seus sistemas de ensino preparando-os para responderem a essa demanda hegemonicamente anunciada ao mundo como fundamental e absolutamente necessária. Mecanismos de acreditação de escolas como internacionais, adoção de programas como o IB por sistemas oficiais de ensino e realização de testes que servem como passaporte para acesso de estudantes às universidades como faz a Cambridge International Examinations, são exemplos de projetos que marcam bem o alinhado compasso da Educação Básica e Superior em direção à internacionalização.

No caso do Brasil, que desde o governo de Fernando Henrique Cardoso (1995-2003) já vinha apresentando sinais de abertura para um modelo de educação ajustado ao conjunto de orientações externas, agora com o governo Temer, as ações passam a ser ainda mais declaradamente alinhadas às recomendações internacionais, sobretudo aquelas originadas dos organismos multilaterais cujo interesse maior é o econômico. Exemplos que indicam esta orientação são as recentes medidas oficiais que impuseram a alteração no texto da Lei de Diretrizes e Bases da Educação Nacional para possibilitar a chamada reforma do Ensino Médio (Lei 13.415/2017) e a aprovação do texto da Base Nacional Comum Curricular - BNCC pelo Conselho Nacional de Educação (BRASIL, 2017). Ambas tiveram participação de organizações de interesse privado e de consultores internacionais na formulação dos textos, trazem conteúdos sustentados por uma concepção educacional de matriz notadamente liberal, assumem o currículo por competências instrumentais como base para a formação escolar, mostram-se receptivas às formas de regulação e avaliação externa, enfim, sinalizam convergência com requerimentos do macroprojeto de internacionalização da educação.

Outro aspecto que vem chamando a atenção neste âmbito é o crescimento no número de escolas brasileiras que oferecem Educação Básica com currículos diretamente associados aos 
movimentos pela internacionalização. Incluem-se neste espaço, as Escolas Internacionais e consequentemente as escolas que oferecem o International Baccalaureate; as escolas que apesar de não ofertarem $\mathrm{o} I \mathrm{~B}$ se vinculam às diferentes agências ou redes de gerenciamento curricular em escala internacional; as chamadas escolas bilíngues que oferecem currículos em dois ou mais idiomas e as escolas privadas que oferecem formação com currículos focados nas chamadas competências interculturais e globais com forte acento no idioma inglês. No website do IB/Brasil, por exemplo, encontra-se que o Programa IB atualmente atende 32 escolas, das quais 15 com o Primary Years Programme, 05 com o Middle Years Programme e 23 com o Diploma Programme. (IB/BRASIL, 2018) A Cambridge Assessment International Education, por sua vez, possui 17 escolas vinculadas nas diferentes regiões do país, além de outras redes que também possuem unidades no Brasil. (CAIE, 2018). Já, as escolas bilíngues são 93, conforme contabilizado por Moura (2017) em seu blog.

\section{PALAVRAS FINAIS}

Em amplo sentido, os resultados dessainvestigação, assim como outros trabalhos de pesquisa que tratam sobre internacionalização da Educação Superior e sobre influências dos organismos multilaterais e grupos privados na formulação da política curricular brasileira, nos autorizam afirmar que desde o início dos anos 1990 várias chaves vêm abrindo portas nos sistemas de ensino do país para o ingresso de interesses internacionais e mais recentemente para os interesses dos grupos transnacionais que colocam a internacionalização da educação e do currículo como marca central de seu projeto político.

Ainda que não se verifique relação mais objetiva entre as ações do sistema oficial de ensino no Brasil e o que propõem as Escolas Internacionais suas redes de apoio e demais projetos nessa perspectiva, observa-se haver evidências de aproximação e alinhamento progressivos, seja por meio da adesão dos mecanismos de avaliação em larga escala, pela busca e/ou acatamento de orientações e recomendações internacionais, por inclusão de abordagens conceituais de conotação liberal nos textos da política curricular, pela implantação de projetos pontuais visando internacionalização a exemplo do que vem fazendo a CAPES/Educação Básica, ${ }^{15}$ ou ainda por medidas oficiais como as que destacamos anteriormente. Em síntese, avalio que o Brasil figura entre os países que possuem 
participação passiva no projeto de internacionalização e, portanto, conforma-se tão somente com a possibilidade de contribuir sem nada exigir em termos de contrapartida para a sociedade brasileira.

Não obstante a necessidade contemporânea de sintonizar-se com os movimentos socioculturais e educacionais que ocorrem em escala mundial e regional, o país, por via de seu sistema de ensino, precisa prioritariamente responder às históricas demandas da sociedade, cujas expectativas têm sido manifestadas em diferentes espaços e esferas públicas, inclusive no vigente Plano Nacional de Educação. São demandas que, alinhadas ao espírito constitucional, exigem a consolidação de um sistema educacional inclusivo, democrático, justo e, portanto, promotor de ampla cidadania a todos/as os brasileiros/as. É preciso, mais que nunca, girar as chaves para colocar em movimento um projeto de educação verdadeiramente nacional.

\section{REFERÊNCIAS}

ADRIÃO, T. Escolas charters nos EUA: contradições de uma tendência proposta para o Brasil e suas implicações para a oferta da educação pública. Educação e Filosofia, Uberlândia, v. 28, n. especial, p. 263-282, 2014.

BEECH, J. Quem está passeando pelo jardim global? Agências educacionais e transferência educacional. In: COWEN, R.t; KAZAMIAS, A. e ULTERHALTER, E. (org.). Educação comparada: panorama internacional e perspectivas. Brasília: UNESCO/ CAPES, p. 413-434, 2012.

BRASIL. Lei 13.415, de 16 de fevereiro de 2017. Disponível em: http:/ /www.planalto.gov. br/ccivil_03/_ato2015-2018/2017/lei/113415.htm. Acesso em: 05 mar. 2018.

BRASIL. Lei de Diretrizes e Bases da Educação Nacional. 2018.Disponível em http:/ /portal.mec.gov.br/index.php?option=comcontent\&view=article\&id=12907:legislacoes\&c atid=70:legislacoes. Acesso em: 05 mar. 2018.

BRUMMITT, N. e KEELING, A. Charting the growth of International Schools. In: PEARCE, R. (ed.). International Education and Schools: Moving Beyond the First 40 Years. London: Bloomsbury Academic, p. 25-36, 2013.

BRUMMITT, N. Facing up to global recession. International School Magazine, v.12 n.1, p. 13-14, 2009.

BRUMMITT, N. International Schools: exponential growth and future implications. International Schools Journal. v. 27, n. 2, p. 35-40, 2007.

BUNNELL, T. Changing landscape of International Schooling: Implications for theory and practice. London: Routledge, 2014. 
BUNNELL, T.; FERTIG, M. e JAMES, C. What is international about International Schools? An institutional legitimacy perspective. Oxford Review of Education; v. 42, n.4, p. 408-423, 2016.

BUNNELL, T. The growth of the International Baccalaureate Diploma Program: Concerns about the consistency and reliability of the assessments. The Educational Forum, n.75, v. 2, 174-187, 2011.

BUNNELL, T. The international baccalaureate and the role of pioneer international schools. In: PEARCE, R. (ed.). International education and schools: Moving beyond the first 40 Years. London: London: Bloomsbury Academic, p. 167-182, 2013.

CAIE. Cambridge Assessment International Education. 2018. Disponível em: http:// www.cambridgeinternational.org/. Acesso em: 09 abr..2018.

CIS. Council of International Schools. 2018. Disponível em: https://www.cois.org/. Acesso em: 09 abr. 2018.

CUSHNER, K. Development and assessment of intercultural competence. In: HAYDEN, M,; LEVY J. e THOMPSON, J. The SAGE handbook of research in International Education. SAGE Publications Ltd, p. 200-216, 2015.

DOHERTY, C. The appeal of the International Baccalaureate in Australia's educational market: A curriculum of choice for mobile futures. Discourse: Studies in the Cultural Politics of Education, n. 30, v.1, p. 73-89, 2009.

FERTIG, M. International school accreditation, Between a rock and a hard place? Journal of Research in International Education, v. 6, n. 3, p. 333-348, 2007. Acesso em: 17 fev. 2018. Disponível em: http://journals.sagepub.com.ez46.periodicos.capes.gov.br/doi/pdf/ $10.1177 / 1475240907083199$.

HAYDEN M. e THOMPSON J. International Schools: Growth and Influence. Paris: UNESCO, 2008.

HAYDEN M. e THOMPSON J. International Schools: antecedents, current issues and metaphors for the future. In: PEARCE, R. (ed.) International education and schools: Moving beyond the first 40 Years. London: Bloomsbury Academic, London, p.3-24, 2013.

HAYDEN M. Transnational spaces of education: the growth of the international school sector. Globalisation, Societies and Education, v. 9, n.2, p. 211-224, 2011.

HAYDEN, M., LEVY, J. e THOMPSON, J. The SAGE handbook of research in International Education. London: SAGE Publications Ltd, 2015.

HILL, I. The history and development of international mindedness. In: HAYDEN, M.; LEVY, J. e THOMPSON, J. The SAGE handbook of research in International Education. London: SAGE Publications Ltd, p. 28-44, 2015.

HOPKINS, D. School improvement for real: educational change and development. Routledge, 2004. 
IB. International Baccalaureate. 2018. Disponível em: http://www.ibo.org/. Acesso em: 09 abr. 2018.

LAUDER, H. International Schools, education and globalization: Towards a research agenda. In: HAYDEN, M.; LEVY, J. e THOMPSON, J. The SAGE handbook of research in International Education. London: SAGE Publications Ltd, p.172-182, 2015.

LEACH, R. International Schools and their role in the field of education. Oxford; New York: Pergamon Press, 1969.

MOURA, S. Educação Bilíngue no Brasil: Plurilinguismo, Interculturalidade e Educação no Brasil. Blog Educação Bilíngue no Brasil, 2017. Disponível em: https:// educacaobilingue.com/info/. Acesso em: 09 abr. 2018.

PEARCE, R. International Education and schools: Moving beyond the first 40 Years. London: Bloomsbury Academic, 2013.

REYNOLDS, D.; CREEMERS, B.; STRINGFIELD, S.; TEDDLIE, C. e SCHAFFER, G. World class schools: International perspectives on school effectiveness. Taylor \& Francis, e-Library. 2004.

ROBERTS, B. Education for a different world: How international education responds to change. In: HAYDEN, M.; LEVY, J. e THOMPSON, J. The SAGE handbook of research in International Education. London: SAGE Publications Ltd, p. 88-107, 2015.

SUCHMAN M. C. Managing legitimacy: Strategic and institutional approaches. Academy of Management Review. v, 20, n. 3 p. 571-610, 1995.

TERWILLIGER, R.I. International Schools, cultural crossroads. The educational forum, v. 36, n. 3, 359-363, 1972.

YEMINI, M. Internationalization discourse hits the tipping point: A new definition is needed. Perspectives: Policy and Practice in Higher Education, v.19, n.1, p. 19-22, 2015.

YEMINI, M. Internationalization and global citizenship: Policy and practice in education. Israel: Springer Nature, 2017.

\section{NOTAS}

${ }^{1}$ Convém marcar que existem diferenças conceituais entre internacionalização da Educação Básica (IEB) e internacionalização dos currículos da Educação Básica (ICEB). No alcance da pesquisa não encontrei um conceito para IEB tampouco projetos que propõem sua internacionalização. Nesse nível de ensino, o movimento é, essencialmente, pela internacionalização dos currículos.

${ }^{2}$ A utilização de textos de pesquisa feitas em contextos internacionais não é uma opção. Deve-se ao fato de não haver estudos no Brasil que discutem este objeto de conhecimento no âmbito da problemática da internacionalização da educação. 
${ }^{3}$ Durante o texto utilizarei a sigla ICEB para designar: Internacionalização dos Currículos da Educação Básica.

${ }^{4}$ Suchman (1995, p. 547), citado pelos autores aos quais me refiro, argumenta que a legitimidade é uma percepção ou suposição generalizada de que as ações de uma entidade são desejáveis, próprias ou apropriadas em algum sistema socialmente construído de normas, valores, crenças e definições. No caso em pauta, Suchman se refere aos sistemas de educação.

${ }^{5}$ Hayden e Tompson (2008) alertam para a dificuldade que é categorizar as EI por tipologias. Afirmam que Leash (1969), o primeiro a categorizá-las, logo reconheceu as limitações de sua classificação. Que em 1981 Sanderson defendeu a existência de 07 tipologias e Ponisch, em 1987, que eram 11 os tipos de EI.

${ }^{6}$ Hayden e Tompson (2008) destacam a dificuldade de precisar o surgimento das escolas internacionais, mas apontam as experiências da Museru English Medium Preparatory School e do International The college atspring grove como referências. Avaliam que a criação da International School of Geneva e da International Yokobama School, ambas em 1924 para atender predominantemente filhos de pais expatriados, podem ser consideradas as primeiras experiências mais próximas dos modelos como se caracterizam as IE hoje.

${ }^{7}$ Yemini (2017, p. 102) recorre a outros pesquisadores para afirmar que "These schools often incorporate the development of global mindedness or global citizenship into their mission statements, implying that they prepare their students to become members of a global society".

${ }^{8}$ Existem várias outras organizações sem ou com fins lucrativos prestando serviços educacionais semelhantes, como por exemplo: The Institute of International Education (IIE), The Council on International Educational Exchange (CIEE), The AFS Intercultural Programs, The International Educator (TIE), The TES Global, The International School Consultancy e a Search Associate.

${ }^{9}$ Tendo em vista as limitações do texto não detalharei o objetivo e a caracterização de cada programa que integra o IB. Para isso, sugiro a leitura das obras: The SAGE Handbook of Research in International Education, organizada por Mary Hayden, Jack Levy and Jeff Thompson (2015) e Internationalization and Global Citizenship: Policy and Practice in Education, de Miri Yemini (2017).

${ }^{10}$ Os dez atributos listados por Cushner (2015, p. 200) são respectivamente: estudantes com mentalidade internacional, conhecedores das questões locais e globais, empáticos, de pensamento crítico, comunicadores, assumem riscos, cuidam-se, possuem espírito aberto, são equilibrados, capazes de tomar decisões e responsáveis em relação ao trabalho e a vida. (Tradução livre do autor).

${ }^{11}$ Para Hill (2015), dentre os princípios e valores que em séculos passados inspiraram a filosofia dos movimentos pela IM (International-mindeness) como herança das civilizações Grecooriental anciãs e que agora estão sendo absorvidos pelo IB quanto ao perfil dos alunos estão: a consciência dos direitos humanos combinada com o senso de responsabilidade social, a busca da equidade social e a participação democrática na tomada de decisão, a compreensão e apreciação das diferenças culturais, o pluralismo, o espírito de cuidado, de cooperação e de solidariedade entre povos e nações, o espírito empreendedor, a criatividade, a sensibilidade quanto à igualdade de gênero; a abertura de mentalidade para mudanças; o envolvimento com as questões da proteção do meio ambiente e do desenvolvimento sustentável. 
${ }^{12}$ Para Yemini (2015, p. 127), o currículo é composto por seis grupos de componentes: uma primeira língua, incluindo literatura internacional, uma segunda língua, um módulo denominado "Indivíduos e Sociedades", ciências experimentais, matemática ou informática e artes. Outras três matérias obrigatórias constituem elementos centrais do currículo: um curso de Teoria do Conhecimento que visa estimular o pensamento crítico com ênfase em várias abordagens e métodos filosóficos; um ensaio extensivo de 4000 palavras entendido como atividade de pesquisa e desenvolvimento de redação visando preparar estudantes para o nível universitário; e o requisito de Ação de Criatividade e Serviço (CAS) que incentiva os alunos a participarem de atividades esportivas, serviço comunitário e atividades não tradicionais ou culturalmente comuns. Os alunos escolhem um componente curricular de cada grupo sendo três no nível superior e três no nível padrão. Os alunos podem fazer exames em um dos três idiomas: inglês, francês ou espanhol. A avaliação envolve algumas tarefas avaliadas internamente e culmina nos exames externos estabelecidos pelo IB. (Tradução livre do autor)

${ }^{13}$ Fertig (2007) lembra que o IB não é o único a oferecer programa de certificação internacional às escolas. A International General Certificate of Secondary Education (IGCSE), no âmbito da Cambridge International Examinations e a New England Association of Schools and Colleges também realizam trabalho semelhante, assim como várias outras.

${ }^{14}$ Tendo em vista as limitações do texto não explicito os objetivos de cada programa, todavia, as obras cujos autores são citados aparecem como referenciais importantes para aprofundamento.

${ }^{15}$ Refiro-me particularmente aos projetos que fiz referência em outro texto dessa mesma pesquisa, quais sejam: o PLI - Programa de Licenciaturas Internacionais que envolveram a participação de Portugal com dez universidades e França com duas, entre 2009 e 2015, o Programa de Desenvolvimento Profissional para Professores de Língua Inglesa (PDPI) em parceria com os EUA; de Física (PDPFís) com a Suíça; o de Alemão (PDPA) com Alemanha e Áustria; o de Matemática (PDPM) com a França; e o de Francês (PDPF) em parceria com a França. Além destes, o programa Professor Assistente de Língua Portuguesa nos EUA (FLTA), o Programa de Ensino de Inglês como uma Língua Estrangeira (IOE) em parceria com a Inglaterra e o Programa de Desenvolvimento Profissional para Professores em Portugal (PDPP).

Submetido: $11 / 04 / 2018$

Aprovado: 12/09/2018

Contato:

Rua Pirineus, 90, Apto 702B, Córrego Grande Florianópolis $|\mathrm{SC}|$ Brasil

CEP. 88.037-615 